\title{
Estudo das representações sociais da maconha entre agentes comunitários de saúde
}

\author{
Study of the social representations of the marijuana \\ among communitarian health's agents
}

Ludgleydson Fernandes de Araújo ${ }^{1}$

Alessandra Ramos Castanha 2

Airton Pereira do Rêgo Barros 3

Christiane Ramos Castanha 4

\footnotetext{
1 Programa de Pósgraduação em Psicologia Social, Departamento de Psicologia, Centro de Ciências Humanas, Letras e Artes, UFPB. Cidade Universitária, Campus I, Conjunto Castelo Branco, 58059-900, João Pessoa PB.

ludgleydson@yahoo.com.br

2 USP, Ribeirão Preto.

3 Universidade Federal

de Uberlândia.

4 Universidade Federal

Rural de Pernambuco.
}

Abstract In view of the increasing excessive use of psychoactive substances, in particular the marijuana in the Brazilian reality, the current research had as objective to verify the social representations of communitarian health's agents (ACS's) regarding the marijuana's use. Seventy ACS's, including both male and female genders; with average age of 26 years participated in this study. It was utilized as instruments semi-structured interviews and the Test of Free Association of Words (TALP). The data acquired by the interviews was categorized by the Bardin's analysis of thematic content (1977) whereas the data from the TALP was processed by the Tri-Deux-Mots software through the factorial analysis of correspondence. The obtained results suggested representations of the marijuana as a hallucinogen plants and drug, which can alter the human metabolism. Regarding the consequences on the user's life, the majority of the ACS's objected the attitude of violence, which causes health and family problems; and thus contributing to the initiation to drug's use and addiction. In conclusion, it is important the intervention of the ACS's on the preventive health education with the goal of decrease the excessive use of drugs.

Key words Marijuana, Communitarian agents of health, Social representations
Resumo Tendo em vista o aumento do uso abusivo de substâncias psicoativas, em particular a maconha, na realidade brasileira, a presente pesquisa teve como objetivo verificar as representações sociais de agentes comunitários de saúde (ACS's) acerca do uso da maconha. Participaram 70 ACS's, de ambos os sexos, com média de idade de 26 anos. Foram utilizados como instrumentos: entrevistas semi-estruturadas e o Teste de Associação Livre de Palavras (Talp). Os dados das entrevistas foram categorizados pela análise de conteúdo temática de Bardin (1977) e os Talp foram processados pelo software Tri-Deux-Mots, por meio da Análise Fatorial de Correspondência. Os resultados sugeriram representações da maconha como planta e droga alucinógena que pode alterar o metabolismo humano. No que se refere às conseqüências na vida do usuário os ACS's objetivaram, de forma majoritária, atitudes de violência que ocasionam problemas relacionados à saúde e à família, contribuindo para iniciação a outras drogas e dependência. Concluiu-se pela importância da intervenção dos ACS's na educação preventiva em saúde, com o intuito de diminuir o uso indevido de drogas.

Palavras-chave Maconha, Agentes comunitários de saúde, Representações sociais 


\section{Introdução}

Este trabalho teve por objetivo verificar as representações sociais da maconha por parte de agentes comunitários de saúde (ACS's), tendo em vista a importância do papel dos ACS's enquanto multiplicadores de informações na educação, na saúde e na prevenção primária ao uso indevido de substâncias psicoativas.

A questão relacionada ao uso indevido de drogas na atualidade é alvo de debates e questionamentos nos diversos segmentos da sociedade. O fenômeno da utilização de substâncias psicoativas tem suscitado preocupação, considerando-se que o seu uso provoca uma pluralidade de danos, não somente aos usuários, como também aos seus familiares e à sociedade.

De acordo com Bastos ${ }^{1}$, a sociedade brasileira, com seu consumismo desenfreado, tem propagado em suas campanhas publicitárias um apelo subliminar em favor de todos os prazeres e da luta pelo prazer a todo custo, que envolve, mesmo que não explicitamente, o uso de drogas.

De acordo com pesquisa sobre o uso de drogas na realidade brasileira ${ }^{2}$, do Centro Brasileiro de Informações Acerca de Drogas Psicotrópicas (Cebrid), em 107 cidades brasileiras com mais de 200 mil habitantes, constatou-se que $6,9 \%$ das pessoas entrevistadas afirmaram ter utilizado a maconha pelo menos uma vez na vida; destes, observa-se que $1 \%$ afirmou ser dependente da droga.

A atual política de redução do uso abusivo de drogas, implementada pela Secretaria $\mathrm{Na}$ cional Antidrogas 3 (Senad), estabelece uma diferença do usuário e dependente químico para o traficante, determinando que seja evitado qualquer tipo de discriminação ao usuário de droga. É uma política na qual o dependente químico é considerado como ser biopsicossocial que, portanto, necessita de atenção especial por parte dos profissionais de saúde 4 .

O nome científico da maconha é Cannabis sativa. Em latim, Cannabis significa cânhamo, que denomina o gênero da família da planta, e sativa, que significa plantada ou semeada, indica a espécie e a natureza do desenvolvimento da planta. É originária da Ásia Central, com extrema adaptação ao clima, à altitude e ao solo, apesar de apresentar uma variação de $1 \%$ a $15 \%$ quanto à conservação das suas propriedades psicoativas, dependendo da região em que for produzida, já que requer clima quente e seco e umidade adequada do solo $5,6,7,8,9$.
Autores como MaCrae e Simões 10 dissertam que, na realidade brasileira, o usuário de maconha está em constante situação de estigmatização social, assédio social e violência. Com relativa freqüência, as ações preventivas, no âmbito do uso de psicotrópicos, não levam em consideração os aspectos biopsicossociais e culturais que estão intrinsecamente relacionados às drogas.

O relatório da Organização das Nações Unidas 11 destaca que o cultivo e o consumo abusivo da Cannabis continuam a ser difundidos na América do Sul. A maconha cultivada na região é, principalmente, destinada ao comércio de drogas ilícitas nos países produtores e países vizinhos. A Colômbia continua sendo o produtor principal da Cannabis que é exportada à Europa e à América do Norte, embora as apreensões mais significativas da droga sejam feitas no Brasil e no Paraguai.

O Ministério da Saúde vem definindo, ao longo do tempo, estratégias que visam ao fortalecimento da rede de assistência aos usuários de maconha e de outras drogas, com ênfase na reabilitação e reinserção social dos mesmos ${ }^{12}$.

Neste sentido, destaca-se o papel do agente multiplicador de informações preventivas ao uso abusivo de drogas nas comunidades, exercido pelos ACS's, realizando um canal de comunicação entre a população e os gestores em saúde13.

Com relação às ações de prevenção ao uso indevido de drogas atualmente propostas pelo Ministério da Saúde, pode-se citar o Programa de Saúde da Família (PSF). O PSF pode funcionar como um catalisador de ações de prevenção, promoção e recuperação da saúde das pessoas com problemas relacionados à maconha, assim como a outras drogas, de forma integral e contínua. Desta forma, é necessário investir em ações que procurem uma formação diversificada e consistente para toda a equipe do PSF, com relação aos elementos determinantes do processo saúde/doença.

O PSF é formado, basicamente, por uma equipe multiprofissional, composta por médico, enfermeiro, auxiliar de enfermagem e agentes comunitários de saúde. É no último grupo, o dos ACS's, que a presente pesquisa foi focalizada, tendo em vista que eles desempenham um papel fundamental na prevenção do consumo de drogas e no tratamento dos usuários nas comunidades, sendo esta uma de suas funções determinadas pelo Ministério da Saúde, por serem um elo essencial na construção do 
vínculo entre a equipe e as famílias e no processo de vigilância à saúde, a fim de acompanhar e intervir nos grupos vulneráveis ao adoecimento e às condições socioambientais desfavoráveis.

O agente comunitário de saúde, por ser um morador da comunidade, representa uma riqueza de possibilidades, pois conhece as pessoas que atende, fala a mesma linguagem dos que o procuram, passa por situações parecidas e compartilha crenças com os membros da região onde atua. Uma orientação dada por um cidadão nestas condições conta com credibilidade que, dificilmente, as palavras de um técnico da saúde atingiriam.

Diante das premissas já mencionadas, este estudo pretendeu verificar as representações sociais da maconha, no contexto do campo da saúde preventiva, entre os ACS's. Esta investigação poderá contribuir para o conhecimento das diversas facetas que compõem o consumo de drogas e para a formação de profissionais que lidem com a temática e com a formulação/implementação de políticas públicas e programas de prevenção/tratamento a serem implementados na agenda de combate ao uso indevido de drogas.

\section{Teoria das representações sociais}

As representações sociais (RS), enquanto senso comum, idéias, imagens, concepções e visão de mundo que os atores sociais têm sobre a realidade, emergem como uma realidade concreta no âmbito das ciências sociais. As RS buscam novas bases teóricas para a compreensão da relação indivíduo X sociedade, afastando-se da forma dicotomizada e descontextualizada. Moscovici14 demonstra que os processos por meio dos quais os indivíduos representam o mundo são extremamente dinâmicos entre a subjetividade e o mundo social dos indivíduos.

Deste modo, uma representação social não pode ser compreendida como processo cognitivo individual, uma vez que é reproduzida no intercâmbio das relações e comunicações sociais. O referido autor ainda menciona que o objeto, seja ele humano, social, material ou uma idéia, será apreendido por intermédio da comunicação 14, 15, 16.

As representações sociais são como sistemas de interpretação que regem nossa relação com o mundo e com os outros, orientando e organizando nossas condutas. Elas estão liga- das a sistemas de pensamento mais amplos, ideológicos ou culturais, a estado de conhecimentos científicos, assim como à condição social e à esfera da experiência privada e afetiva dos indivíduos 17 .

Com as representações sociais, o conhecimento do senso comum passou a receber a atenção necessária, posto que era visto como conhecimento confuso, inconsistente, desarticulado e fragmentado. Em relação ao conhecimento científico, o senso comum era situado num pólo extremo e oposto: uma espécie de saber selvagem, profano, ingênuo ${ }^{18}$. A teoria tem como pressuposto verificar o conhecimento comum produzido por intermédio das comunicações de determinados grupos sociais.

Na elaboração das RS faz-se necessária a contribuição de dois fatores - a objetivação e a ancoragem - que são responsáveis pela interpretação e atribuição de significados do objeto social, neste estudo, a maconha. Para Moscovici19, esses fatores são condições sine qua non, pois ambos colaboram na maneira como o social transforma um conhecimento em representação e na maneira como esta transforma o social, indicando a interdependência entre a atividade psicológica e suas condições sociais.

Para Sá20, o processo de representar socialmente emerge da materialização dos conceitos abstratos, comuns ao grupo, o que se denomina objetivação, ao mesmo tempo em que cria um contexto inteligível ao objeto representado ou sua integração cognitiva, o que é denominado de ancoragem. Neste processo, a representação tem por objetivo transformar em familiar o não familiar.

É muito importante conhecer as representações sociais que os ACS's apresentam sobre a maconha, uma vez que eles podem desenvolver intervenções no âmbito da prevenção/promoção em saúde junto aos usuários e seus familiares. Assim sendo, o presente estudo teve como objetivo apreender as RS da maconha entre agentes comunitários de saúde.

\section{Método}

\section{Participantes}

O presente estudo foi realizado no município de Ipojuca, localizado na Zona da Mata Sul do Estado de Pernambuco. Participaram desta pesquisa 70 de um total de 104 agentes comunitários de saúde, escolhidos aleatoriamente, 
de forma não probabilística, intencional e acidental, de ambos os sexos ( $13 \%$ do masculino e $87 \%$ do feminino), com média de idade de 26 anos. Ressalta-se que os critérios de inclusão da amostra deram-se a partir da disposição dos ACS's em participar voluntariamente, e por estarem inseridos no Programa de Agentes Comunitários (Pacs) do município pesquisado.

\section{Instrumentos}

Para a coleta dos dados, foram utilizadas entrevistas em profundidade e a técnica de associação livre de palavras. As entrevistas foram divididas em duas partes: a primeira, constituída de itens referentes à identificação sociodemográfica dos participantes, definindo o seu perfil; e a segunda, composta por uma questão norteadora, a saber: "O que você sabe sobre a maconha?". Também foi utilizada a técnica de associação livre de palavras, bastante difundida no âmbito da Psicologia Social, principalmente quando se trabalha com o suporte teórico das RS, uma vez que possibilita acesso aos conteúdos periféricos e latentes $21,22,23,24$. Neste estudo, foi utilizado um estímulo indutor - "maconha" - previamente definido, tendo como pressuposto o estado atual da arte, bem como os atores sociais que fazem parte desta investigação (agentes comunitários de saúde).

\section{Procedimentos de coleta dos dados}

Realizou-se um estudo piloto, com o intuito de verificar a boa adequação dos instrumentos, e verificou-se a validade semântica dos mesmos. Em seguida, efetuou-se o estudo definitivo. Inicialmente, foi mantido contato com a coordenação da Secretaria de Saúde, com a finalidade de obter a listagem dos ACS's. Posteriormente, verificou-se a disposição dos mesmos de participar, de forma voluntária, desta pesquisa.

Oportunamente, explicitaram-se os objetivos e a necessidade do uso do gravador, e foram garantidos o anonimato e a confiabilidade das respostas, indicando que seriam analisadas em conjunto. É válido mencionar que foram respeitados os parâmetros éticos, de acordo com a resolução 196/96 do Conselho Nacional de Saúde, que rege as pesquisas com seres humanos.

O primeiro instrumento aplicado foi a técnica de associação livre de palavras, seguida de entrevista. Os instrumentos foram aplicados, de forma individual, na própria Secretaria de Saúde, por um pesquisador previamente treinado e qualificado. O tempo de aplicação foi, em média, de 18 minutos para cada participante. Informa-se, ainda, que não houve recusa por parte de nenhum ACS. Antes da aplicação do estímulo, foi feita uma simulação, utilizando-se de um exemplo, com o intuito de familiarizar o participante sobre a funcionalidade do instrumento. Em seguida, foi apresentado o estímulo indutor, seguido da questão "O que lhe vem à mente (cabeça) quando digo a palavra maconha? Fale as cinco primeiras palavras que, para o senhor (a), lembram a maconha.” É válido mencionar que na presente pesquisa convencionou-se o tempo máximo de um minuto para a evocação das palavras associadas ao estímulo indutor, perfilando um minuto por cada participante para responder ao teste de associação livre de palavras.

\section{Análise dos dados}

No que se refere à interpretação dos dados desta pesquisa, utilizou-se a análise de conteúdo temática Bardin'25, cujo objetivo é compreender o sentido das comunicações e suas significações explícitas e/ou ocultas. Seu procedimento visa, ainda, a obter a sistematização e descrição do conteúdo das mensagens que permitem a inferência de conhecimentos relativos às condições de produção/recepção (variáveis inferidas), interpretados quantitativamente por meio da análise das freqüências e percentuais.

A análise das unidades temáticas por meio dessa técnica pressupõe o desenvolvimento das seguintes etapas operacionais: constituição do corpus; leitura flutuante; composição das unidades de análise; codificação e recortes; categorização e descrição das categorias. Após a leitura flutuante do corpus e a emersão das categorias empíricas, elas foram codificadas e validadas internamente por quatro pesquisadoresjuízes que trabalham com a técnica.

Os dados coletados pela técnica de associação livre foram processados pelo software TriDeux-Mots 26 , versão 2.2, que permite a visualização gráfica tanto das variáveis fixas (sexo, idade e estado civil), como das variáveis de opinião (crenças, estereótipos, enfim, o conhecimento prático enunciado pelos participantes frente ao estímulo indutor), analisadas por meio da Análise Fatorial de Correspondência (AFC). O principio básico da AFC consiste em 
destacar eixos que explicam as modalidades de respostas, mostrando estruturas constituídas de elementos do campo representacional, ou seja, os conteúdos apreendidos nos discursos dos ACS’s diante dos estímulos indutores.

\section{Resultados e discussão}

As representações sociais sobre a maconha, elaboradas pelos ACS's, foram analisadas com base no material coletado pelas entrevistas e ponderadas pela análise temática de conteúdo, de acordo com o consenso de quatro pesquisadores, que resultaram em quatro categorias empíricas e 20 subcategorias.

A tabela 1 ilustra os dados relativos a "Concepções/Descrições da Maconha (CDM)”. Pode-se notar que os ACS's destacaram a maconha, de forma majoritária, como uma "droga" (33\%) que apresenta propriedades "alucinógenas" (26\%) e como uma "planta" (22\%), como se pode verificar nas falas dos atores sociais a seguir:

É uma droga, [...] a maconha é uma droga [...]. Eu acho que a pessoa viaja [...], a pessoa fica contente [...]. Tem gente que planta [...] e as folhas são utilizadas para fazer o cigarro [...]. O pouco que eu sei é que ela altera todo o metabolismo da pessoa, [...] que é um tipo de alucinógeno [...], como se tivessem nas nuvens [...], como se as coisas fossem mais gostosas [...]. Diminui a ansiedade [...] porque ela atinge os pulmões [...], atinge também o cérebro, a corrente sanguinea.

De forma semelhante aos ACS's, Sucar 27 argumenta que a maconha é uma droga alucinógena, tendo em vista que é capaz de provocar alterações no funcionamento do cérebro (sistema nervoso central), de modo que pode desencadear nos seus usuários efeitos psíquicos como delírios (falso juízo da realidade) e alucinações (percepção sem objeto).

Observa-se que os atores sociais desta pesquisa ancoraram suas RS da maconha como uma planta. De fato, trata-se de uma combinação de flores e folhas da planta, conhecida pela nomenclatura científica Cannabis sativa, cujo principal princípio ativo é o THC (tetrahidrocanabinol). Sua concentração na planta depende, sobretudo, da forma como a Cannabis foi cultivada, em que tipo de clima e solo6, 7, 8, 9.

De acordo com o observado na tabela 2 acerca de "Conseqüências na Vida do Usuário de Maconha (CVUM)", nota-se que a maioria dos ACS's destaca, sobretudo, que a utilização da maconha pode levar a "dependência física" $(28 \%)$ e a "violência" (21\%).

Entre as unidades temáticas das falas dos ACS’s, foi possível destacar as representações sociais das conseqüências do uso da maconha:

[...] A maconha é ruim porque é um vício. [...] É prejudicial à saúde e depois que vicia não tem mais jeito, [...] está fazendo muito mal para as pessoas, [...] está destruindo lares, famílias, levando muitos adolescentes à morte. [...] Cada vez que usa mais maconha quer experimentar outras drogas. [...] Eles perdem o trabalho, o controle dentro das próprias casas e ficam violentos. [...] Não quer ter um apoio da família, não quer ouvir o que a família quer conversar, [...] dar uma orientação pra ele.

Na presente investigação, os ACS’s destacaram a dependência física ocasionada pelo uso indevido da maconha. De forma antagônica aos participantes desta pesquisa, Bergeret e Leblanc $^{6}$ salientam que o uso continuado da maconha é mais constante no desenvolvimento de uma dependência psíquica, e não física, como verificado nas representações sociais dos agentes comunitários de saúde.

Não há consenso entre os pesquisadores acerca de qual tipo de dependência é predominante nos usuários de maconha. No entanto, a

\begin{tabular}{lcr}
\hline $\begin{array}{l}\text { Tabela } \mathbf{1} \\
\text { Concepções/descrições da maconha. }\end{array}$ & \multicolumn{2}{c}{ ACS's } \\
\hline Categoria e subcategorias & $f$ & $\%$ \\
\hline Droga & 28 & 33 \\
Alucinógena & 22 & 26 \\
Altera metabolismo & 16 & 19 \\
Planta & 18 & 22 \\
Total & $\mathbf{8 4}$ & $\mathbf{1 0 0}$
\end{tabular}

Tabela 2

Conseqüências na vida dos usuários de maconha.

\begin{tabular}{lrc}
\hline Categoria e subcategorias & \multicolumn{2}{c}{ ACS's } \\
& $f$ & $\%$ \\
\hline Familiar & 28 & 18 \\
Dependência física & 25 & 16 \\
Iniciação às drogas & 24 & 15 \\
Prejudicial à saúde & 26 & 17 \\
Violência & 33 & 21 \\
Auto-destruição & 20 & 13 \\
Total & $\mathbf{1 5 6}$ & $\mathbf{1 0 0}$ \\
\hline
\end{tabular}


dependência psíquica é freqüentemente associada ao uso abusivo da Cannabis7.

As representações sociais acerca das conseqüências do uso da maconha foram ancoradas na esfera orgânica, em elementos como "prejudicial à saúde" e "dependência física". Isto provavelmente se deve à prática profissional dos ACS's junto à educação preventiva em saúde, de modo que o discurso acerca da maconha16 permeie a formação do conhecimento compartilhado por seu grupo de pertença e de afiliação.

De acordo com o V Levantamento Nacional Sobre o Uso de Drogas Psicotrópicas Entre Estudantes do Ensino Fundamental e Médio da Rede Pública de Ensino28, pode-se verificar uma significativa utilização das drogas lícitas, como o álcool e o tabaco, consumidos, respectivamente, por $65,2 \%$ e $24,9 \%$ dos estudantes pesquisados.

De forma antagônica aos ACS's, que mencionaram a maconha como iniciação às drogas, verificou-se que apenas 5,9\% dos estudantes pesquisados pelo levantamento já utilizaram a droga. Os dados sugerem que as drogas lícitas são responsáveis pela maior utilização de psicotrópicos, provavelmente por causa da acessibilidade legal e econômica.

Os dados da tabela 3 revelam as "Causas do Uso de Maconha (CUM)": os ACS's apontam, de forma majoritária (28\% e $25 \%$, respectivamente), "curiosidade" e "influência de amigos". Os ACS's representaram as causas do uso da maconha nas suas falas abaixo:

[...] A pessoa começa por uma curiosidade [...], por uma timidez a pessoa se torna dependente [...]. É uma droga que vicia uma pessoa que às vezes quer coragem [...] e acha que usando aquilo vai ser melhor, vai se soltar [...]. É muito fácil encontrar maconha, por todo canto a pessoa que usa pode comprar [...], os amigos, às vezes, oferecem. [...] O adolescente vai e usa, vai pela cabeça dos outros [...].

De modo consonante com as RS dos ACS's acerca das causas do uso da maconha, Lapate 29 argumenta que há uma série de razões que motivam as pessoas a fazer uso de drogas, a saber: curiosidade ou desejo de experimentar os efeitos prazerosos das drogas; influência do grupo de afiliação, para integrar-se socialmente; vivenciar a sensação de correr riscos; testar a vulnerabilidade e os próprios limites.

Observa-se que o uso de drogas psicotrópicas é algo que acompanha a história da humanidade, sendo uma prática milenar do homem experimentar estados alterados da consciência, por diversos motivos: fugir de situações desagradáveis, produzir sensações prazerosas, vivenciar experiências transcendentais, religiosas, místicas e curativas ${ }^{7}$.

No entanto, presencia-se na atualidade a veiculação de campanhas publicitárias que, de forma subliminar, fazem associação do uso de drogas ao sucesso profissional e econômico, de modo a gerar, sobretudo nos jovens, a curiosidade de utilizar substâncias psicoativas 1 .

Faz-se necessário uma intervenção preventiva em saúde pelos ACS's, respaldada no conhecimento científico, com o intuito de educar para prevenir, que desmistifique o uso de substâncias psicoativas e aponte sua ação no organismo humano, de modo a amenizar a iniciação ao uso de drogas pela comunidade-alvo.

A tabela 4 possibilita a visualização do "Tratamento do Usuário de Maconha (TUM)". Os ACS's destacaram o "tratamento médico", com 34\%. Em seguida, os atores sociais apontaram as "campanhas preventivas", com $26 \%$, permitindo inferir que, provavelmente, as indicações devem-se à prática desses atores sociais na educação em saúde.

As falas dos atores sociais desta pesquisa foram:

\section{Tabela 3}

Causas do uso de maconha.

\begin{tabular}{lcc}
\hline Categoria e subcategorias & \multicolumn{2}{c}{ ACS's } \\
& $f$ & $\%$ \\
\hline Fuga da realidade & 14 & 10 \\
Prazer & 20 & 14 \\
Curiosidade & 40 & 28 \\
Influência de amigos & 35 & 25 \\
Disponibilidade & 13 & 09 \\
Diversão & 19 & 14 \\
Total & $\mathbf{1 4 1}$ & $\mathbf{1 0 0}$ \\
\hline
\end{tabular}

Tabela 4

Formas de tratamento dos usuários de maconha.

\begin{tabular}{lrr}
\hline Categoria e subcategorias & \multicolumn{2}{c}{ ACS's } \\
& \multicolumn{1}{c}{$f$} & $\%$ \\
\hline Médico & 38 & 34 \\
Psicossocial & 27 & 24 \\
Grupos de apoio & 18 & 16 \\
Campanhas preventivas & 29 & 26 \\
Total & $\mathbf{1 1 2}$ & $\mathbf{1 0 0}$ \\
\hline
\end{tabular}


[...] Porque por mais que as pessoas mostrem as palestras, os meios de comunicação, rádio, televisão, as pessoas não querem acreditar [...]. Essas pessoas que usam maconha precisam de um tratamento médico, [...] uma desintoxicação [...]. Tem que ter apoio de grupos, tem esses grupos para usuários de drogas que podem ajudar [...] um tratamento com a família, e as pessoas que usam a maconha, com profissionais de psicologia [...].

Quanto às "Formas de Tratamento dos Usuários de Maconha”, verificada nas RS dos ACS's, pode-se perceber que se trata de uma visão embasada, de forma majoritária, no modelo médico tradicional que prioriza os aspectos da farmacodependência em detrimento dos aspectos históricos, sociais e culturais relacionados às questões motivacionais para a utilização da substância psicoativa naquela comunidade.

As políticas de prevenção/intervenção ao uso abusivo de drogas não podem se isolar de uma visão genérica das substâncias psicoativas e devem ter consciência da amplitude do fenômeno, com o intuito de elaborar estratégias de intervenção que levem em conta a realidade sócio-histórica, antropológica, farmacológica e psicossocial da comunidade-alvo7.

A carência de estudos consistentes sobre substâncias psicoativas na realidade brasileira dificulta a implementação de intervenções que priorizem as particularidades regionais de acessibilidade aos programas de educação, saúde e peculiaridades culturais, que se refletem diretamente no consumo de drogas psicotrópicas $^{30}$. Tal fato interfere no Pacs, do Ministério da Saúde, quanto ao modelo eficaz de intervenção na saúde preventiva desenvolvida pelos ACS's frente ao uso da maconha e outras substâncias psicoativas.

No que diz respeito às campanhas preventivas elencadas pelos ACS's, as intervenções terapêuticas produzem impacto positivo no âmbito da prevenção em saúde, quando monitoradas de forma contínua e regular. No entanto, é fato que na realidade brasileira tais campanhas são comumente realizadas com intuito ideológico/político, de modo que não há um acompanhamento quanto à eficácia na melhoria da prevenção em saúde 5,31 .

Os resultados coletados por meio do teste de associação livre de palavras, como instrumento de apreensão de significados do conhecimento prático, possibilitaram, juntamente com as variáveis fixas, a emersão de campos semânticos sobre as representações sociais da maconha, conforme pode ser observado no gráfico 1, por intermédio dos dois fatores nele contemplados (F1 e F2) e analisados pela Análise Fatorial de Correspondência.

O fator 1 (F1), na linha horizontal, em negrito, concerne ao fator majoritário de maior poder explicativo, com $46 \%$ da variância total das respostas. Observa-se que os ACS's contribuíram de forma significativa nesse fator, com 305 palavras evocadas. No que tange ao fator 2 (F2), na linha vertical, em itálico, ele apresenta $24 \%$ da variância total das respostas.

Percebe-se que houve maior contribuição dos ACS's do gênero masculino na explicação desse fator, com 110 palavras evocadas. No que tange às idades, os ACS's que compreendem a faixa etária maior ou igual a 30 anos contribuíram, de forma majoritária, para o fator 2 , com 156 palavras evocadas. Na totalidade, os dois fatores têm poder explicativo de $70 \%$ de significância, portanto possuem parâmetros estatísticos com consistência interna e fidedignidade, tendo em vista pesquisas realizadas no âmbito das RS24.

$\mathrm{Na}$ parte horizontal inferior do gráfico 1, em negrito, encontra-se o fator 1, relacionado ao campo semântico das RS da maconha (palavras em negrito com terminação 1) elaboradas pelos ACS's do gênero feminino, casadas, na

\section{Gráfico 1}

Análise fatorial de correspondência das RS da maconha.

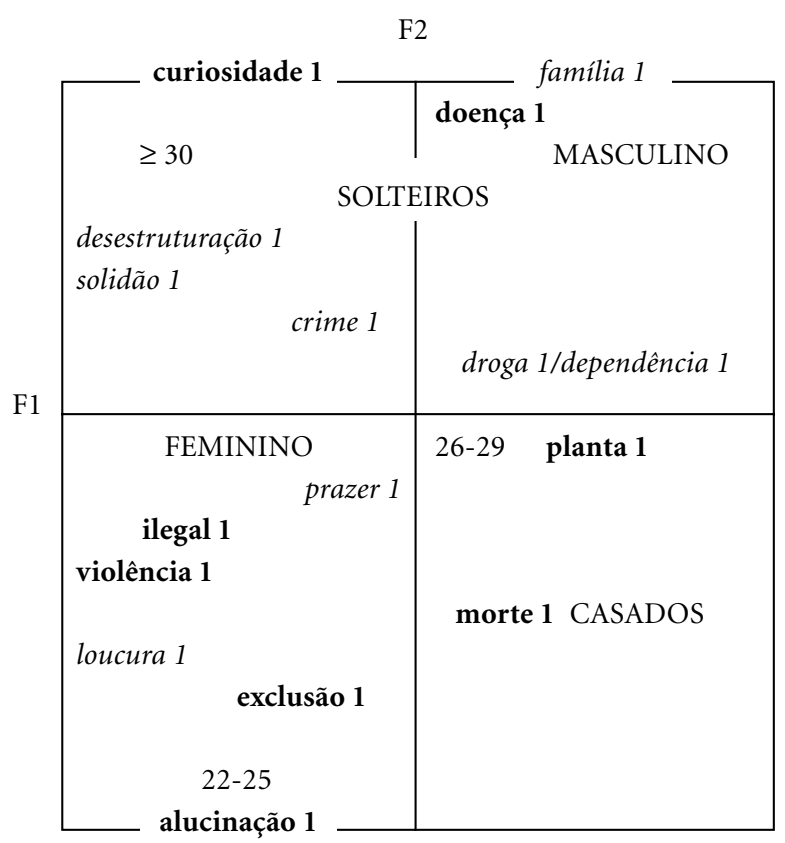


faixa etária de 22 a 25 anos. Eles ancoraram suas representações como uma substância psicoativa derivada de uma "planta" que desencadeia efeitos como "alucinação", e que o seu uso é "ilegal" na realidade brasileira, sendo responsável pela "exclusão", "violência" e "morte".

Ainda nesse fator, destacam-se os ACS's solteiros, na faixa etária maior ou igual a 30 anos, que ancoraram suas representações (palavras em negrito na parte superior horizontal) acerca das causas do uso da maconha devido à "curiosidade" dos usuários pelos efeitos que a substância psicoativa pode desencadear. No entanto, ela pode propiciar ao usuário "doenças", quando consumida de forma abusiva. Salientase que, na técnica da entrevista, tais elementos constitutivos das RS também foram verificados nas causas e conseqüências do uso da maconha entre os atores sociais desta pesquisa.

No que tange ao fator 2 , na parte vertical esquerda, em itálico, percebe-se que os ACS's do gênero feminino, que compreendem a faixa etária de 22 a 25 anos, objetivaram de forma semelhante aos dados da entrevista acerca das causas do uso da maconha relacionadas aos aspectos "prazerosos" que a droga ocasiona aos seus usuários. No entanto, eles mencionaram que, por outro lado, a droga, quando administrada de forma abusiva, pode levar o seu usuário à "loucura".

De forma consoante com as causas do uso da maconha elencadas pelos ACS's, motivadas pelas sensações prazerosas, o mesmo também pôde ser verificado entre estudantes universitários concluintes de Saúde e Direito, que mencionaram em suas representações sociais acerca da maconha a droga como produtora de efeitos de prazer aos seus usuários $5,9,31$.

No fator 2, na parte vertical, em itálico, verificam-se as representações socais apreendidas entre os ACS's do gênero masculino, que atribuíram ao uso da maconha a "solidão" e a prática de atitudes delitivas e "criminosas", sendo fruto da "desestruturação" psicossocial e afetiva em que se encontram inseridos os usuários da substância psicoativa.

É fundamental a consciência de que a dependência degrada a condição humana do indivíduo, e esforços devem ser desenvolvidos para amenizar a venda ilegal de drogas, posto que o uso destas substâncias pode contribuir para a prática de atos anti-sociais e delitivos ${ }^{32}$.

Ainda no fator 2, na parte vertical à direita, em itálico, denota-se o campo semântico elaborado por ambos os gêneros, solteiros, que com- preendem a faixa etária maior ou igual a 30 anos, que representaram a maconha (palavras em itálico com terminação 1) como uma "droga" que pode proporcionar conseqüências, tais como "dependência" e problemas "familiares".

De forma semelhante aos dados encontrados nas entrevistas, os ACS's, também no teste de associação, ancoraram suas representações sociais nos elementos concernentes a "problemas familiares", "prejudicial à saúde" e "violência”. Deste modo, as RS verificadas entre os atores sociais desta pesquisa acerca da maconha aparecem como um conhecimento que não se caracteriza por uma contraposição ao saber científico, havendo uma dialética entre o conhecimento consensual (senso comum) e o reificado (científico) ${ }^{16}$.

De acordo com Freitas 33 , um ambiente familiar dominado por conflitos, pela falta de regras ou pelo desinteresse dos pais pela vida dos filhos representa um fator de risco ao uso de drogas. Assim, o apoio socioafetivo e psicológico da família é fundamental para que seja desenvolvida uma rede de proteção ao uso indevido da maconha e de outras drogas.

Neste sentido, os danos relacionados ao uso de drogas não se apresentam somente no indivíduo usuário. São direta ou indiretamente afetados os familiares e a sociedade em geral, por meio de comprometimentos físicos, psíquicos e sociais. Assim, o uso indevido de drogas é considerado, na atualidade, um problema de saúde pública mundial, que demanda intervenções na prevenção primária, secundária e terciária, bem como no tratamento dos usuários e familiares ${ }^{34}$.

Ademais, os resultados apreendidos por este instrumento, além de corroborar, complementam os dados oriundos das entrevistas acerca das RS da maconha. Neste sentido, a maconha foi representada como uma droga que pode trazer inúmeras conseqüências psicossociais, profissionais, familiares e orgânicas. De modo que é fundamental e necessária a inserção dos ACS's na educação preventiva em saúde, como interlocutores entre gestores em saúde e a comunidade, intervindo nos fatores de proteção ao uso de drogas.

\section{Considerações finais}

O presente trabalhou versou sobre as RS da maconha entre ACS's. Os dados apreendidos entre os ACS's possibilitaram representações 
consensuais e particularidades, de acordo com cada vivência de atuação na saúde preventiva.

Evidenciou-se, neste estudo, que os ACS's possuem um conhecimento elaborado acerca da maconha pautado na prevenção ao uso indevido da droga, tendo em vista que ela pode provocar inúmeras conseqüências aos usuários, à família e à sociedade. As práticas cotidianas dos atores sociais, sua intervenção profissional na promoção em saúde, determinam e embasam as suas RS acerca da maconha.

Neste sentido, a presente pesquisa demonstrou que se faz necessária a implantação de cursos de capacitação permanente, que ofereçam subsídios aos ACS's para melhor intervir na prevenção ao uso abusivo de drogas, posto que se presenciou uma lacuna no que concerne à qualificação destes promotores de saúde acerca dos efeitos e conseqüências dos psicotrópicos, tendo em vista o aumento crescente da demanda existente na comunidade-alvo, devido ao uso de drogas lícitas e ilícitas.

O uso de substâncias psicoativas tem crescido de forma vertiginosa na realidade brasilei- ra, principalmente o consumo de drogas lícitas (álcool, tabaco e medicamentos). Deste modo, se faz necessária a implantação de programas de promoção e prevenção ao uso indevido de drogas, que priorizem a população-alvo e suas condições psicossociais e afetivas, bem como questões familiares, ideológicas e políticas, compreendendo a problemática nos seus fatores biopsicossociais e culturais, uma vez que apenas a promulgação de leis repressoras e a adoção de modelos importados de outros países têm demonstrado total ineficácia no combate ao uso de drogas.

Recomenda-se maior número de estudos sobre a realidade brasileira, que contemplem o uso de substâncias psicoativas e suas variáveis psicoafetivas, sociocognitivas e farmacológicas, intervindo no âmbito da saúde coletiva, com o intuito de minimizar o uso abusivo da maconha, por meio da implementação de políticas públicas de educação e promoção em saúde, em que os ACS's se apropriem do papel de integração entre gestores e comunidade.

\section{Colaboradores}

LF Araújo, AR Castanha, AP Barros e CR Castanha participaram igualmente de todas as etapas da elaboração do artigo.

\section{Referências}

1. Bastos MT. Combate ao narcotráfico. Rev CulturaImae 2003; 4(9):6-11.

2. Carlini E, Galduróz JCF, Noto AR. I Levantamento domiciliar sobre o uso de drogas psicotrópicas no Brasil: estudo envolvendo as 107 maiores cidades do País. São Paulo: Cebrid/Unifesp; 2001.

3. Secretaria Nacional Antidrogas (Senad). Um guia para a família. Brasília: Senad; 2001.

4. Uchoa PRYM. Sistema Nacional Antidrogas. Rev Cultura-Imae 2003; 4(9):22-9.

5. Araújo LF. As drogas agindo no organismo humano. Jornal Mundo Jovem no 357; 2005 Jun 1; p. 14.

6. Bergeret J, Leblanc J. Toxicomanias: uma visão multidisciplinar. Porto Alegre: Artes Médicas; 1991.

7. Bucher R. Drogas e drogadição no Brasil. Porto Alegre: Artes Médicas; 1995. 
8. Nahas GG. A maconha ou a vida. Rio de Janeiro: Nórdica; 1986.

9. Gontiès B, Araújo LF. Os aspectos legais da maconha no contexto universitário: um estudo das representações sociais. In: Coutinho MPL, Lima AS, Fortunato ML, Oliveira FB, organizadores. Representações sociais: abordagem interdisciplinar. João Pessoa: EdUFPB; 2003. p. 293-311.

10. MaCrae E, Simões JA. Rodas de fumo: o uso da maconha entre camadas médias urbanas. Salvador: EdUFBA; 2000.

11. Organização das Nações Unidas (ONU). Report of the international narcotics control board. New York: United Nations; 2001.

12. Ministério da Saúde (MS). Programa agentes comunitários de saúde. Brasília: Ministério da Saúde; 2000.

13. Silva JA, Dalmaso ASW. Agente comunitário de saúde: o ser, o saber, o fazer. Rio de Janeiro: Editora Fiocruz; 2002.

14. Moscovici S. A representação social da Psicanálise. Rio de Janeiro: Zahar; 1978.

15. Moscovici S. Psychologie Sociale. Paris: PUF; 1984.

16. Moscovici S. Representações sociais: investigações em Psicologia Social. Petrópolis: Vozes; 2003.

17. Jodelet D. Representações sociais. Rio de Janeiro: EdUerj; 2001.

18. Nóbrega SM. Sobre a teoria das representações sociais. In: Moreira ASP, organizadora. Representações sociais. Teoria e prática. João Pessoa: EdUFPB; 2001. p. 55-87.

19. Moscovici S. Représentations sociales: un domaine en expansive. In: Jodelet D, organizador. Les représentation sociales. Paris: PUF; 1988. p. 42-9.

20. Sá CP. Representações sociais: o conceito e o estado atual da teoria. In: Spink MJ, organizador. O conhecimento no cotidiano. As representações sociais na perspectiva da Psicologia Social. São Paulo: Brasiliense; 1993. p. 19-43.

21. Di Giacomo JP. Aspects méthodologiques de l'analyse des répresentations sociales. Cahiers de Psychologie Cognitive 1981; 1(1):397-422.

22. Le Boudec G. Contribuition à la méthodologie d'étude des représentations sociales. Curr Psychol Cogn 1984; (4):245-72.

23. De Rosa AS. Sur l'usage des associations libres dans l'étude des représentations sociales de la maladie mentale. Connexions 1988; (51):27-50.
24. Nóbrega SM, Coutinho MPL. O teste de associação livre de palavras. In: Coutinho MPL, Lima AS, Fortunato ML, Oliveira FB, organizadores. Representações sociais: abordagem interdisciplinar. João Pessoa: EdUFPB; 2003. p. 67-77.

25. Bardin L. Análise de conteúdo. Lisboa: Edições 70; 1977.

26. Cibois P. L'analyse factorielle. Paris: PUF; 1998. (Collection Que sais-je?).

27. Sucar JM. As drogas e seus efeitos. In: Secretaria Nacional Antidrogas (Senad), organizadora. Formação de multiplicadores de informações preventivas sobre drogas. 2a ed. Florianópolis: LED/UFSC; 2002. p. 2669.

28. Galduróz JCF, Noto AR, Fonseca AM, Carlini EA. V Levantamento nacional sobre o uso de drogas psicotrópicas entre estudantes do ensino fundamental e médio da rede pública de ensino nas 27 capitais brasileiras. São Paulo: Cebrid /Unifesp; 2004.

29. Lapate V. A família e as drogas. In: Secretaria Nacional Antidrogas (Senad), organizadora. Formação de multiplicadores de informações preventivas sobre drogas. 2a ed. Florianópolis: LED/UFSC; 2002. p. 156-92.

30. Noto AR, Formigoni ML. Drogas psicotrópicas e a política de saúde pública no Brasil. Ciência Hoje 2002; 181(4):30-5.

31. Coutinho MPL, Araújo LF, Gontiès G. Uso da maconha e suas representações sociais: estudo comparativo entre universitários. Psicol. estud 2004; 9(3):46977.

32. Limongi CL. Drogas - aspectos legais e jurisprudência. In: Secretaria Nacional Antidrogas (Senad), organizadora. Formação de multiplicadores de informações preventivas sobre drogas. 2a ed. Florianópolis: LED/UFSC; 2002. p. 297-308.

33. Freitas CC. As drogas na adolescência. In: Secretaria Nacional Antidrogas (Senad), organizadora. Formação de multiplicadores de informações preventivas sobre drogas. 2a ed. Florianópolis: LED/UFSC; 2002. p. 95-113.

34. Dias JC. O tratamento do uso indevido de drogas. In: Secretaria Nacional Antidrogas (Senad), organizadora. Formação de multiplicadores de informações preventivas sobre drogas. 2a ed. Florianópolis: LED/ UFSC; 2002. p. 277-93.

Artigo apresentado em 2/08/2005

Artigo aprovado em 17/11/2005

Versão final apresentada em 23/01/2006 